\title{
The effect of D-cycloserine on immediate vs. delayed extinction of learned fear
}

\author{
Julia M. Langton ${ }^{1,3}$ and Rick Richardson ${ }^{2}$ \\ ${ }^{7}$ Adult Cancer Program, Prince of Wales Clinical School, University of New South Wales, Sydney 2052, Australia; ${ }^{2}$ School of Psychology, \\ University of New South Wales, Sydney 2052, Australia
}

\begin{abstract}
We compared the effect of D-cycloserine (DCS) on immediate (10 min after conditioning) and delayed ( $24 \mathrm{~h}$ after conditioning) extinction of learned fear in rats. DCS facilitated both immediate and delayed extinction when the drug was administered after extinction training. However, DCS did not facilitate immediate extinction when administered prior to extinction training (i.e., when the interval between drug administration and shock was reduced). In addition, administering five, but not two, shocks prior to extinction training disrupted the facilitating effects of DCS on delayed extinction. These results suggest that aversive experiences prior to DCS administration can prevent it from facilitating extinction.
\end{abstract}

Pavlovian fear conditioning involves pairing an initially neutral stimulus, such as a tone (the conditioned stimulus [CS]), with an innately aversive stimulus, such as shock (the unconditioned stimulus [US]), such that subsequent presentation of this CS elicits a number of fear-related behaviors. These learned responses to the CS can be reduced through the process of extinction, which involves repeated presentations of the CS without the US. Although it is widely accepted that NMDA receptors (NMDArs) are critically involved in extinction (e.g., Falls et al. 1992; Baker and Azorlosa 1996; Sotres-Bayon et al. 2007), recent research has shown that a previous experience of extinction to a context or CS can influence the NMDAr involvement in subsequent extinction of that same CS or context (e.g., Laurent et al. 2008; Chan and McNally 2009; Langton and Richardson 2009). For example, D-cycloserine (DCS, a partial agonist at the glycine site of the NMDAr) facilitates extinction (Walker et al. 2002; Ledgerwood et al. 2003; Woods and Bouton 2006), but not re-extinction of learned fear (Langton and Richardson 2008; Yamada et al. 2009). The aim of the current series of experiments was to investigate other factors that may influence NMDAr involvement in extinction.

Recently, there have been a number of studies comparing extinction that occurs immediately after fear conditioning to extinction that occurs following a delay. In the first study to systematically examine this, rats received conditioning followed by extinction training $10 \mathrm{~min}, 1 \mathrm{~h}, 24 \mathrm{~h}$, or $72 \mathrm{~h}$ later (Myers et al. 2006). Rats extinguished $72 \mathrm{~h}$ after conditioning exhibited renewal, reinstatement, and spontaneous recovery of the extinguished fear at a subsequent test, whereas rats in the 10-min condition did not. Those findings were interpreted as evidence that immediate extinction induces erasure of the original fear conditioning memory, whereas extinction after a delay results in the formation of a new CS-no US inhibitory memory that exists alongside the excitatory CS-US memory. In other words, it was suggested that the mechanisms underlying extinction may be different depending on the interval between conditioning and extinction. This distinction between immediate and delayed extinction is clearly theoretically important as well as being clinically important given the controversy regarding interventions, such as debriefing immediately following traumatic events with

${ }^{3}$ Corresponding author.

E-mail j.langton@unsw.edu.au; fax 61-2-9385-1430.

Article is online at http://www.learnmem.org/cgi/doi/10.1101//m.1927310. the aim of preventing the emergence of anxiety disorders such as post-traumatic stress disorder (for review, see McNally et al. 2003). Because of the importance of this finding, a number of subsequent studies examined the consequences of varying the interval between conditioning and extinction. While some of these studies failed to support the results reported by Myers et al. 2006 (e.g., Norrholm et al. 2008; Schiller et al. 2008; Woods and Bouton 2008; Chang and Maren 2009; Kim and Richardson 2009), some reported at least partial support for their findings. For example, Maren and Chang (2006) were able to conceptually replicate these findings if baseline levels of freezing prior to immediate extinction were low. In that case, rats exhibited good extinction retention and no spontaneous recovery $1 \mathrm{wk}$ later. In contrast, if pre-extinction baseline levels of freezing were high, rats exhibited poor extinction retention whenever they were tested. Maren and Chang (2006) concluded that the level of fear present at the start of extinction training is a more important determinant of the efficacy of extinction than is the interval between fear conditioning and extinction training.

Regardless of whether immediate extinction is more effective than delayed extinction, and whether immediate extinction leads to erasure of the fear memory, the length of time between conditioning and extinction is important for other reasons. For example, Cain et al. (2005) examined the effect of nifedipine (an L-type voltage-gated calcium channel [LVGCC] blocker) on extinction that occurred immediately, 1, 3, or $24 \mathrm{~h}$ after fear conditioning. Nifedipine impaired extinction that occurred after a delay (i.e., 1, 3, and $24 \mathrm{~h}$ ) but had no effect on immediate extinction. This result suggests that although LVGCCs are involved in delayed extinction (also see Cain et al. 2002), they may not be necessary for immediate extinction. Therefore, it seems that the interval between conditioning and extinction influences the neurobiological mechanisms involved in extinction. The current experiments examined whether a similar dissociation between immediate and delayed extinction would be observed for the partial NMDAr agonist DCS.

Pavlovian fear conditioning and extinction paradigms were used to examine the effect of DCS on immediate and delayed extinction in adult male Sprague-Dawley rats (ARC, Perth, Australia). The CS was a 10 -sec white noise (noise levels increased by $8 \mathrm{~dB}$ when the CS was presented), and the US was a $0.6-\mathrm{mA}$, 1-sec shock delivered through the grid floor. The two distinct experimental chambers (contexts $\mathrm{A}$ and $\mathrm{B}$ ) and the fear conditioning, extinction training, and test parameters were the same as 
described previously (see Werner-Seidler and Richardson 2007). Briefly, fear conditioning (context A) consisted of five CS-US pairings (2 min intertrial interval [ITI]), extinction training (context B) consisted of six CS-alone presentations (2 min each; 2 min ITI), and test (context B) consisted of one 2-min CS presentation. An ABB design was used to reduce pre-CS freezing during extinction training and test. Rats were injected with either saline or DCS (15 mg/kg; Sigma) prior to or following the extinction training session (for further details, see Langton and Richardson 2008).

The measure of fear used was freezing, which was defined and scored as described previously (see Langton and Richardson 2008, 2009); 30\% of the test data was scored by a second observer blind to the study details ( $r s>0.90$ ). Data were analyzed using independent sample $t$-tests and analysis of variance (ANOVA). Post-hoc tests were done with Tukey's honestly significant difference (HSD) procedure. There were no group differences in pre-CS freezing at the start of extinction or at test across the three experiments (largest $F_{(1,38)}=2.71, P=0.11$ ).

Experiment 1 compared the effect of DCS on extinction that occurred either immediately $(10 \mathrm{~min})$ after conditioning or following a delay $(24 \mathrm{~h})$. Either $10 \mathrm{~min}$ or $24 \mathrm{~h}$ after fear conditioning rats received extinction training, and were subsequently injected with DCS or saline and tested for fear of the CS $24 \mathrm{~h}$ later. Therefore, this experiment examined the effect of DCS on long-term extinction retention (as opposed to within-session extinction) following immediate vs. delayed extinction training. All groups showed evidence of within-session extinction (Fig. 1A) with statistical analysis revealing a significant effect of trial, $F_{(1,38)}=5.22, P<0.05$, but no significant interaction effects $(F \mathrm{~s}<1)$ or other main effects reached significance. At test the following day, regardless of whether extinction occurred immediately after conditioning or after a $24 \mathrm{~h}$ delay, DCS-treated rats
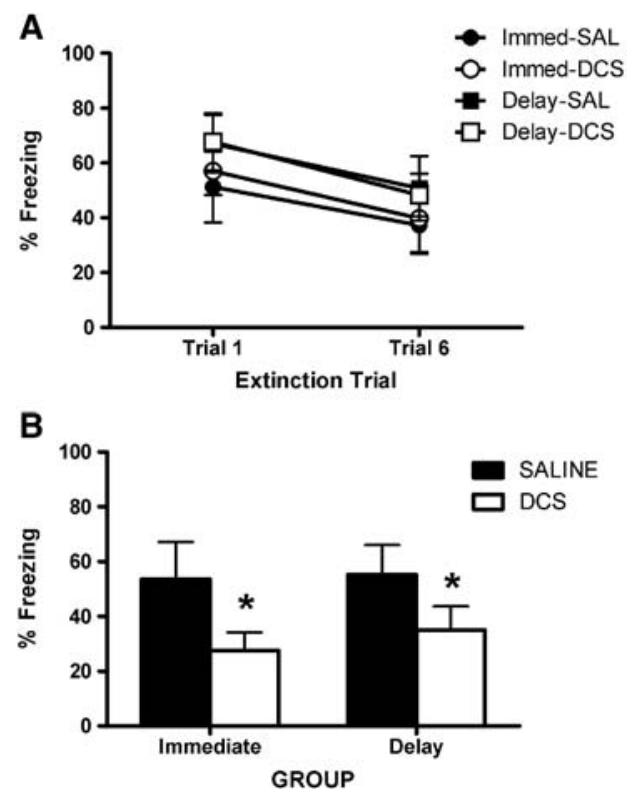

Figure 1. Extinction training and test data from Experiment 1. This experiment demonstrates that DCS facilitates extinction that occurs immediately (10 $\mathrm{min})$ or following a delay $(24 \mathrm{~h})$ after fear conditioning (when DCS is injected after the extinction training session). This is shown by lower levels of fear at test in rats injected with DCS compared to saline. Rats were in one of four groups: Immed-SAL $(n=10)$, Immed-DCS $(n=10)$, Delay-SAL $(n=10)$, or Delay-DCS $(n=12)$. $(A)$ Mean $( \pm$ SEM) freezing of rats during trial 1 and trial 6 of extinction training. (B) Mean ( \pm SEM) freezing in response to the CS during test. * Indicates a significant difference. exhibited less fear than did saline-treated rats (Fig. 1B); analysis of the test data revealed a significant effect of drug, $F_{(1,38)}=$ $5.72, P<0.05$, but no effect of time or drug-by-time interaction $(F \mathrm{~s}<1)$.

Experiment 1 showed that DCS facilitates both immediate and delayed extinction when DCS is administered following extinction training. Specifically, DCS facilitated immediate extinction when the interval between fear conditioning and drug administration was $35 \mathrm{~min}$. To further explore the effect of DCS on immediate extinction, we compared the effect of administering DCS either prior to or following immediate extinction training. In Experiment 2, all rats were extinguished 10 min after fear conditioning and tested for CS-elicited freezing the following day. Rats were injected with DCS or saline either immediately before or after the extinction session. The saline-prior and salineafter groups were collapsed (analysis revealed no significant difference between the groups; $t_{(9)}=0.01, P=0.99$ ) such that there were three groups-Saline, DCS-prior, and DCS-after. All groups showed evidence of within-session extinction (Fig. 2A); statistical analysis revealed a significant effect of trial, $F_{(1,25)}=67.31$, $P<0.001$, but no effect of group or trial-by-group interaction $(F \mathrm{~s}<1)$. At test the following day, rats injected with DCS after immediate extinction exhibited less freezing compared to salinetreated animals and rats injected with DCS prior to immediate extinction training (Fig. 2B). A one-way ANOVA confirmed this and revealed a significant effect of group $\left(F_{(2,25)}=10.14, P<\right.$ 0.05). Post-hoc tests showed that this effect was due to both the saline and DCS-prior groups being significantly different to the DCS-after groups ( $P \mathrm{~s}<0.05)$; there was no significant difference between the saline and DCS-prior groups $(P=0.75)$.

Experiment 2 showed that DCS did not facilitate immediate extinction when it was administered 10 min following the last CS-US pairing, but did facilitate immediate extinction when it was administered $35 \mathrm{~min}$ after the last CS-US pairing. This suggests that the interval between fear conditioning and DCS administration may influence the effect of DCS on extinction. In order to examine whether recent fear conditioning (i.e., associative learning) is the crucial factor is reducing the efficacy of DCS on extinction or whether any recent aversive experience can prevent DCS from facilitating extinction, Experiment 3 examined the effect of DCS on delayed extinction that was preceded by footshock. Fear conditioning (context A) occurred on day 1 and on day 2 rats were returned to context $\mathrm{A}$ and given either two or five shocks ( $1 \mathrm{sec}, 0.6 \mathrm{~mA}$ with $30 \mathrm{sec}$ ITI); $10 \mathrm{~min}$ later they were injected with DCS or saline and received extinction training in context B and were tested for fear of the CS on day 3.

Regardless of drug or number of shocks delivered, all rats showed evidence of within-session extinction (Fig. 3A). Statistical analysis confirmed this description of the data and revealed a significant effect of trial, $F_{(1,38)}=52.17, P<0.001$, but no effect of drug $(F<1)$, and no significant interaction effects (largest $\left.F_{(1,38)}=2.69, P=0.11\right)$. At test the following day, both DCSand saline-treated rats in the five-shock condition showed comparable levels of freezing. In contrast, in the two-shock condition DCS-treated rats appeared to show less fear than saline-treated rats (Fig. 3B). Statistical analysis of the test data revealed a significant effect of drug, $F_{(1,38)}=8.69, P<0.05$, no effect of shock $(F<1)$, and a drug-by-shock interaction, $F_{(1,38)}=5.91, P<0.05$. Post-hoc tests showed that the interaction was due to a significant difference between saline and DCS rats in the two-shock condition $(P<0.05)$, but not in the five-shock condition $(P=0.98)$. No other post-hoc comparisons were significant. These results show that DCS facilitates delayed extinction that is preceded by two, but not five, footshocks.

Taken together, these results demonstrate that DCS facilitates both immediate and delayed extinction. However, if there 

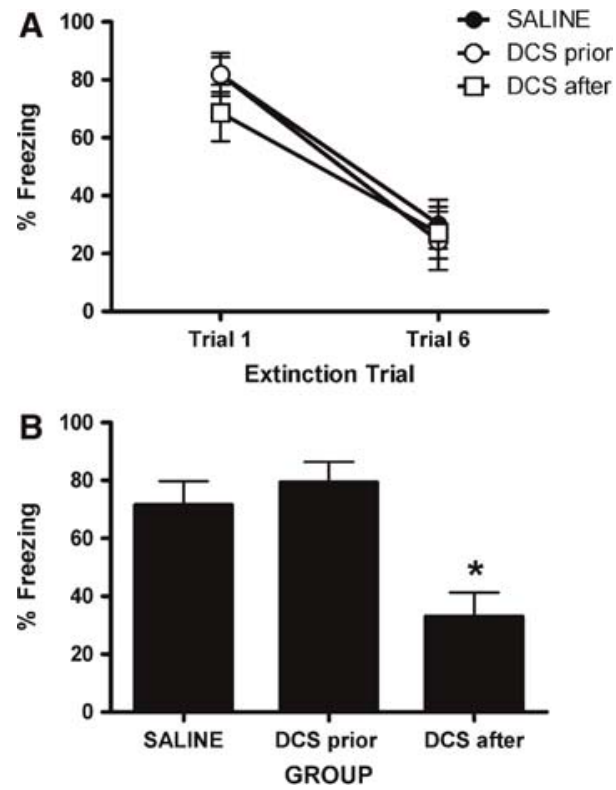

Figure 2. Extinction training and test data from Experiment 2. This experiment showed that DCS only facilitates extinction when administered after immediate extinction training (that is, 35 min after fear conditioning). This is demonstrated by the significant difference between the saline $(n=11)$ and DCS-after groups $(n=9)$, but not between the saline and DCS-prior groups $(n=8)$ at test. $(A)$ Mean ( \pm SEM) freezing of rats during trial 1 and trial 6 of extinction training. (B) Mean ( \pm SEM) freezing in response to the CS during test. * Indicates a significant difference compared to the other two groups.

is a short interval ( $\sim 10 \mathrm{~min})$ between DCS administration and strong stimulation (fear conditioning or five shock presentations), then DCS facilitation of extinction is disrupted. Importantly, neither fear conditioning nor shock presentations prior to extinction training disrupted within-session extinction, which is an important requirement for DCS facilitation effects (e.g., Weber et al. 2007; Bouton et al. 2008). That is, the recent experience of fear conditioning/shock did not prevent within-session extinction, but it did prevent the DCS enhancement of the consolidation of this learning.

The current research represents an investigation of the neurotransmitter systems involved in immediate extinction and suggests that immediate extinction, like delayed extinction, is NMDAr dependent unless DCS administration occurs soon after ( $\sim 10 \mathrm{~min}$ ) fear conditioning or footshock presentations. This result is similar to the results reported by Cain et al. (2005) who found that the interval between conditioning and nifedipine administration influenced the effect of the drug on extinction. When there was no interval, the drug had no effect (immediate group) and when the interval was largest, the drug produced the greatest impairment (3- and 24-h groups). Likewise, in the current experiments when the interval between fear conditioning/shock and drug administration was short $(\sim 10 \mathrm{~min})$ DCS did not facilitate extinction, but when the interval was longer $(\sim 35 \mathrm{~min}$ or $24 \mathrm{~h})$ DCS did facilitate extinction.

The finding that DCS does not facilitate extinction when closely preceded by strong stimulation (such as the shock used during fear conditioning) is consistent with the relative lack of evidence showing that DCS facilitates fear conditioning in comparison to other types of learning. For example, DCS has been shown to facilitate a number of associative learning tasks including conditioned taste aversion in rats (Land and Riccio 1997) and trace eyeblink conditioning in rabbits using an air-puff US
(Thompson et al. 1992; Thompson and Disterhoft 1997). DCS has also been found to facilitate reconsolidation of a fear conditioning memory (Lee et al. 2006), passive avoidance learning (Monahan et al. 1989; Land and Riccio 1997; but see Tomilenko and Dubrovina 2007), and a number of spatial learning tasks (Monahan et al. 1989; Baxter et al. 1994; Quartermain et al. 1994; Lelong et al. 2001). Additionally, compared to the large body of research showing DCS enhancement effects on extinction (see Norberg et al. [2008] for a meta-analysis) there are only a handful of studies showing that DCS enhances CS or contextual fear conditioning (Silvestri and Root 2008; Kalisch et al. 2009; Waddell et al. 2010; but see Yamamoto et al. 2008).

Based on the relative lack of evidence that DCS facilitates fear conditioning compared to extinction, Davis et al. $(2005,2006)$ proposed that repeated presentations of aversive stimuli (that occur during fear conditioning, for example) may increase endogenous levels of glycine and D-serine such that the application of DCS has no benefit (i.e., does not enhance learning). Specifically, it has been suggested that when the glycine site of the NMDAr is saturated, the capacity for positive modulation of the NMDAr is reduced, which makes it unlikely that application of a drug such as DCS will be able to enhance learning and/or memory consolidation (Davis et al. 2005). The impact of increased endogenous glycine on the effects of NMDAr agonists has been demonstrated in two recent studies. For example, Li et al. (2009) used whole cell voltage-clamp recordings to explore the effects of strong and weak synaptic inputs on the action of positive modulators of the glycine site of the NMDAr in rat hippocampal slices. They found that strong synaptic stimulation increased endogenous glycine levels and prevented NMDAr agonists from positively modulating NMDAr-mediated responses (i.e., excitatory postsynaptic currents [EPSCs]), whereas NMDAr agonists potentiated EPSCs when weak synaptic stimulation was applied.
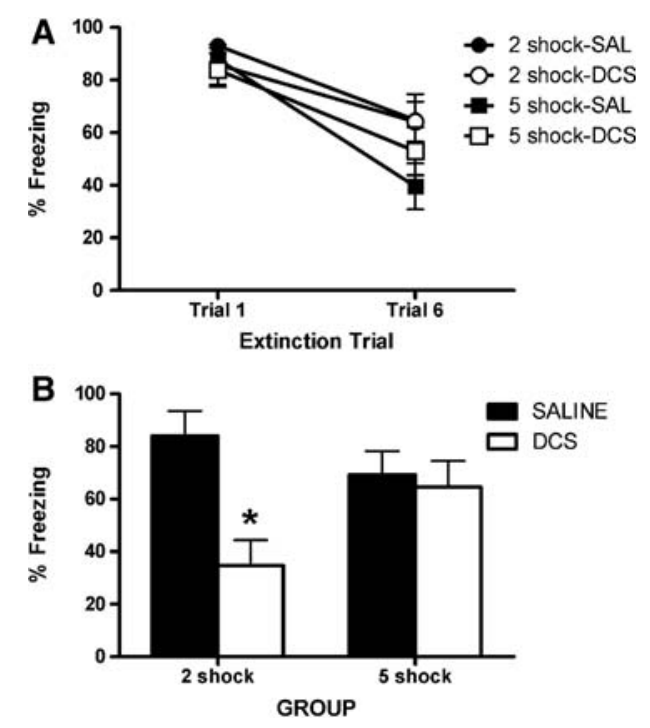

Figure 3. Extinction training and test data from Experiment 3. In Experiment 3, rats were given two or five footshocks $10 \mathrm{~min}$ prior to extinction training; DCS or saline was injected immediately before extinction training. This experiment shows that DCS facilitates delayed extinction that is preceded by two, but not five, footshocks. This is demonstrated by comparable levels of fear in the five-shock-SAL ( $n=$ $11)$ and five-shock-DCS $(n=12)$ groups at test, but a significant difference between the two-shock-SAL $(n=10)$ and two-shock-DCS $(n=9)$ groups. $(A)$ Mean $( \pm$ SEM) freezing of rats during trial 1 and trial 6 of extinction training. $(B)$ Mean $( \pm$ SEM) freezing in response to the $C S$ during test. ${ }^{*}$ Indicates a significant difference to the saline group in the same condition. 
Similarly, Zhang et al. (2008) examined the effect of the glycine site partial agonist GLYX-13 on long-term potentiation (LTP), long-term depression (LTD), and NMDAr-mediated ESPCs in hippocampal slices. They found that GLYX-13 modulation of LTP, LTD, and ESPCs was prevented when D-serine was applied to the hippocampal slices at saturating concentrations. These studies demonstrate that drugs working on the glycine site of the NMDAr are unable to modulate the synaptic plasticity that underlies learning and memory when the glycine site of the NDMAr is saturated. Importantly, the glycine-site of the NMDAr is not saturated under baseline conditions or even following weak synaptic inputs in physiological studies (Bergeron et al. 1998; Li et al. 2009). Therefore, although speculative, a relationship between synaptic inputs/stimulation and levels of endogenous glycine can explain why DCS facilitated extinction following two shocks (i.e., weak stimuli) but not five shocks (i.e., strong stimuli). Further, the current results suggest that any increase in endogenous glycine following repeated shock presentations must be short-lived, as DCS was found to facilitate extinction when delivered $35 \mathrm{~min}$ (but not $10 \mathrm{~min}$ ) following fear conditioning. Studies measuring neural levels of endogenous glycine following aversive stimulation are required to provide direct evidence for the hypothesis that DCS does not facilitate learning when the procedure involves repeated shock presentations because of short-lived saturation at the glycine-site of the NMDAr.

In summary, the current findings contribute to our understanding of the role of aversive stimulation on NMDAr modulating agents, such as DCS, and also contribute to the literature on the neurotransmitter systems involved in immediate vs. delayed extinction. Additionally, determining situations that will influence the effect of DCS on extinction is clinically important given research demonstrating that DCS effectively augments exposure therapy for a number of anxiety disorders (see Norberg et al. 2008 for a meta-analysis). Given the possibility that DCS will be translated into real-world clinical practice, it is vital to understand any potential limitations of the drug. For instance, pre-exposure to DCS or an antidepressant has been found to prevent DCS from enhancing extinction (Parnas et al. 2005; Werner-Seidler and Richardson 2007). The current results show that DCS does not facilitate extinction if it is administered soon after a stressor such as shock or fear conditioning (a clinical analog to this may be trauma or a panic attack), suggesting that DCS may be an inappropriate adjunct for early intervention treatments following trauma. Understanding the circumstances when pharmacological adjuncts to exposure therapy, such as DCS, may be ineffective will assist clinicians and researchers to refine treatment protocols for anxiety disorders in the future.

\section{Acknowledgments}

This research was supported by an Australian Post-Graduate Award (J.M.L.) and Australian Research Council grant DP0985554 (R.R.).

\section{References}

Baker JD, Azorlosa JL. 1996. The NMDA antagonist MK-801 blocks the extinction of Pavlovian fear conditioning. Behav Neurosci 110: 618-620.

Baxter MG, Lanthorn TH, Frick KM, Golski S, Wan R, Olton DS. 1994. D-cycloserine, a novel cognitive enhancer improves spatial memory in aged rats. Neurobiol Aging 15: 207-213.

Bergeron R, Meyer TM, Coyle JT, Greene RW. 1998. Modulation of $\mathrm{N}$-methyl-D-aspartate receptor function by glycine transport. Proc Natl Acad Sci 95: 15730-15734.

Bouton ME, Vurbic D, Woods AM. 2008. D-cycloserine facilitates context-specific fear extinction learning. Neurobiol Learn Mem 90: 504-510.
Cain CK, Blouin AM, Barad M. 2002. L-type voltage-gated calcium channels are required for extinction, but not acquisition or expression, of conditional fear in mice. J Neurosci 22: 9113-9121.

Cain CK, Godsil BP, Jami S, Barad M. 2005. The L-type calcium channel blocker nifedipine impairs extinction, but not reduced contingency effects, in mice. Learn Mem 12: 277-284.

Chan WYM, McNally GP. 2009. Conditioned stimulus familiarity determines effect of MK801 on fear extinction. Behav Neurosci 123: $303-314$.

Chang C, Maren S. 2009. Early extinction after fear conditioning yields a context-independent and short-term suppression of conditional freezing in rats. Learn Mem 16: 62-68.

Davis M, Myers KM, Ressler KJ, Rothbaum BO. 2005. Facilitation of extinction of conditioned fear by D-cycloserine. Curr Dir Psychol Sci 12: 214-219.

Davis M, Ressler K, Rothbaum BO, Richardson R. 2006. Effects of $\mathrm{D}$-cycloserine on extinction: Translation from preclinical to clinical word. Biol Psychiatry 60: 369-375.

Falls WA, Miserendino MJ, Davis M. 1992. Extinction of fear-potentiated startle: Blockade by infusion of an NMDA antagonist into the amygdala. J Neurosci 12: 854-863.

Kalisch R, Holt B, Petrovic P, De Martino B, Kloppel S, Buchel C, Dolan RJ 2009. The NMDA agonist D-cycloserine facilitates fear memory consolidation in humans. Cereb Cortex 19: 187-196.

Kim JH, Richardson R. 2009. Expression of renewal is dependent on the extinction-test interval rather than the acquisition-extinction interval. Behav Neurosci 123: 641-649.

Land CL, Riccio DC. 1997. D-cycloserine, a positive modulator of the NMDA receptor, enhances acquisition of a conditioned taste aversion. Psychobiology 25: 210-216.

Langton JM, Richardson R. 2008. D-cycloserine facilitates extinction the first time but not the second time: An examination of the role of NMDA across the course of repeated extinction sessions. Neuropsychopharmacology 33: 3096-3102.

Langton JM, Richardson R. 2009. The role of context in the re-extinction of learned fear. Neurobiol Learn Mem 92: 496-503.

Laurent V, Marchand AR, Wetsbrook RF. 2008. The basolateral amygdala is necessary for learning but not relearning extinction of context conditioned fear. Learn Mem 15: 304-314.

Ledgerwood L, Richardson R, Cranney J. 2003. Effects of D-cycloserine on extinction of conditioned freezing. Behav Neurosci 117: 341-349.

Lee JL, Milton AL, Everitt BJ. 2006. Reconsolidation and extinction of conditioned fear: Inhibition and potentiation. J Neurosci 26: $10051-10056$

Lelong V, Dauphin F, Boulouard M. 2001. RS 6733 and D-cycloserine accelerate learning acquisition in the rat. Neuropharmacology $\mathbf{4 1}$ : $517-522$.

Li Y, Krupa B, Kang J, Bolshakov VY, Liu G. 2009. Glycine site of NMDA receptor serves as a spatiotemporal detector of synaptic activity patterns. J Neurophysiol 102: 578-289.

Maren S, Chang C. 2006. Recent fear is resistant to extinction. Proc Natl Acad Sci 103: 18020-18025.

McNally RJ, Bryant RA, Ehlers A. 2003. Does early psychosocial intervention promote recovery from posttraumatic stress? Psychol Sci Public Interest 4: 45-79.

Monahan JB, Hanselmann GE, Hood WF, Cordi AA. 1989. D-cycloserine, a positive modulator of the $N$-methyl-D-aspartate receptor, enhances performance of learning tasks in rats. Pharmacol Biochem Behav 34: $649-653$.

Myers KM, Ressler KJ, Davis M. 2006. Different mechanisms of fear extinction dependent on length of time since fear acquisition. Learn Mem 13: 216-223.

Norberg MM, Krystal JH, Tolin DF. 2008. A Meta-analysis of D-Cycloserine and the facilitation of fear extinction and exposure therapy. Biol Psychiatry 63: 1118-1126.

Norrholm SD, Jovanovic T, Vervliet B, Myers KM, Davis M, Rothbaum BO, Duncan EJ. 2008. Timing of extinction relative to acquisition: A parametric analysis of fear extinction in humans. Behav Neurosci 122: $1016-1030$.

Parnas AS, Weber M, Richardson R. 2005. Effects of multiple exposures to D-cycloserine on extinction of conditioned fear in rats. Neurobiol Learn Mem 83: 224-231.

Quartermain D, Mower J, Rafferty MF, Herting RL, Lanthorn TH. 1994. Acute but not chronic activation of the NMDA-coupled glycine receptor with D-cycloserine facilitated learning and retention. Eur J Pharmacol 257: 7-12.

Schiller D, Cain CK, Curley NG, Schwartz JS, Stern SA, LeDoux JE, Phelps EA. 2008. Evidence for recovery of fear following immediate extinction in rats and humans. Learn Mem 15: 394-402.

Silvestri AJ, Root DH. 2008. Effects of REM deprivation and an NMDA agonist on the extinction of conditioned fear. Physiol Behav 93: $274-281$. 
Sotres-Bayon F, Bush DE, LeDoux JE. 2007. Acquisition of fear extinction requires activation of the NR2B-containing NMDA receptors in the lateral amygdala. Neuropsychopharmacology 32: $1929-1940$.

Thompson LT, Disterhoft JF. 1997. Age- and dose-dependent facilitation of associative eyeblink conditioning by D-cycloserine in rabbits. Behav Neurosci 111: 1303-1312.

Thompson LT, Moskal JR, Disterhoft JF. 1992. Hippocampus-dependent learning facilitated by a monoclonal antibody or D-cycloserine. Nature 359: $638-641$.

Tomilenko RA, Dubrovina NI. 2007. Effects of activation and blockade of NMDA receptors on the extinction of a conditioned passive avoidance response in mice with different levels of anxiety. Neurosci Behav Physiol 37: 509-515.

Waddell J, Mallimo E, Shors T. 2010. D-cycloserine reverses the detrimental effects of stress on learning in females and enhances retention in males. Neurobiol Learn Mem 93: 31-36.

Walker DL, Ressler KJ, Lu KT, Davis M. 2002. Facilitation of conditioned fear extinction by systemic administration or intra-amygdala infusions of D-cycloserine as assessed with fear potentiated startle in rats. $J$ Neurosci 22: 2343-2351.

Weber M, Hart J, Richardson R. 2007. Effects of D-cycloserine on extinction of learned fear to an olfactory cue. Neurobiol Learn Mem 87: $476-482$.
Werner-Seidler A, Richardson R. 2007. Effects of D-Cycloserine on extinction: Consequences of prior exposure to imipramine. Biol Psychiatry 62: 1195-1197.

Woods AM, Bouton ME. 2006. D-cycloserine facilitates extinction but does not eliminate renewal of the conditioned emotional response. Behav Neurosci 120: 1159-1162.

Woods AM, Bouton ME. 2008. Immediate extinction causes a less durable loss of performance than delayed extinction following either fear or appetitive conditioning. Learn Mem 15: 909-920.

Yamada D, Zushia K, Wada K, Sekiguchia M. 2009. Pharmacological discrimination of extinction and reconsolidation of contextual fear memory by a potentiator of AMPA receptors. Neuropsychopharmacology 34: $2574-2584$.

Yamamoto S, Morinobu S, Fuchikami M, Kurata A, Kozuru T, Yamawaki S. 2008. Effects of single prolonged stress and D-cycloserine on contextual fear extinction and hippocampal NMDA receptor expression in a rat model of PTSD. Neuropsychopharmacology 33: 2108-2116.

Zhang X, Sullivan JA, Moskal JR, Stanston PK. 2008. A NMDA receptor glycine site partial agonist, GLYX-13, simultaneously enhances LTP and reduces LTD at Schaffer collateral-CA1 synapses in hippocampus. Neuropharmacology 55: 1238-1250.

Received July 5, 2010; accepted in revised form August 18, 2010. 


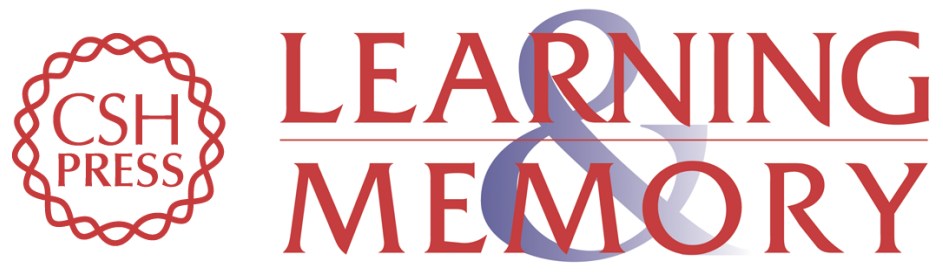

\section{The effect of D-cycloserine on immediate vs. delayed extinction of learned fear}

Julia M. Langton and Rick Richardson

Learn. Mem. 2010, 17:

Access the most recent version at doi:10.1101//m.1927310

References This article cites 44 articles, 12 of which can be accessed free at:

http://learnmem.cshlp.org/content/17/11/547.full.html\#ref-list-1

License

Email Alerting Receive free email alerts when new articles cite this article - sign up in the box at the Service top right corner of the article or click here. 